\title{
DELAY on first antenatal care visit and its associated factors among pregnant women in public health facilities of Debre Markos town, North West Ethiopia
}

Atsede Alle Ewunetie ${ }^{1 *}$, Alemtsehay Mekonnen Munea ${ }^{2}$, Belsity Temesgen Meselu ${ }^{3}$, Muluye Molla Simeneh ${ }^{1}$ and Bekele Tesfaye Meteku ${ }^{4}$

\begin{abstract}
Background: Delay on timely initiation of antenatal care has a great impact on adverse pregnancy out comes. However, evidences in Ethiopia revealed that majority of pregnant mothers did not start their first visit as recommrnded by WHO. The aim of this study was to assess delay and associated factors of first antenatal care visit among pregnant mothers at public health facilities of Debremarkos town, North West Ethiopia.

Methods: An institutional based crosss-sectional study was conducted from February to March, 2014 in public health facilities of Debremarkos town North west Ethiopia. A total of 320 pregnant mothers who were sure of their last menstrual periods were interviewed with a structured questionnaire. Data entry was done using Epi data 3.1 and analysis was done using SPSS version 20. Descriptive statistics, binary and multivariable logistic regression analyses were employed to identify the magnitude and factors associated with delay on timely initiation of the first antenatal care visit.

Results: The proportion of respondents who made their first antenatal care visit after 16 weeks of gestation was found to be 33.4\%. Mothers residing in rural settings ( $A O R=2.8$ [95\% Cl:1.54-5.44]), not attained formal education(AOR $=2.2$ [95\% Cl:1.10-4.68]), with unintended pregnancy (AOR $=3.6[95 \% \mathrm{Cl}: 2.00-6.80]$ ) and who perceived that the right initiation time of the first antenatal care visit is beyond 16 weeks of gestation (AOR $=3.9$ [95\% Cl:1.61-9.76]) were more likely delayed on their first antenatal care visit .

Conclusion: Residence, educational status, intention of pregnancy and perception on the right time of first antenatal care visit initiation were found to be predictors of delay on timely initiatin of first antenatal care visit. Therefore, the Zonal health department should strengthen awareness creation about timely initiation of first antenatal care visit and family planning to prevent unintended pregnancy in the community especially in the rural settings.
\end{abstract}

Keywords: Delay on timely initiation of antenatalcare, Unintended, Pregnancy

\footnotetext{
* Correspondence: atsialle@gmail.com

'Department of Public Health, College of Health Sciences, Debre Markos

University, Debre Markos, Ethiopia

Full list of author information is available at the end of the article
}

(c) The Author(s). 2018 Open Access This article is distributed under the terms of the Creative Commons Attribution 4.0 International License (http://creativecommons.org/licenses/by/4.0/), which permits unrestricted use, distribution, and reproduction in any medium, provided you give appropriate credit to the original author(s) and the source, provide a link to the Creative Commons license, and indicate if changes were made. The Creative Commons Public Domain Dedication waiver (http://creativecommons.org/publicdomain/zero/1.0/) applies to the data made available in this article, unless otherwise stated. 


\section{Background}

Many health problems of pregnant women are preventable, detectable, and treatable if they attained antenatal care (ANC) adequately [1]. The traditional approach of the ANC is a high risk approach which intended to classify pregnant women at low risk or high risk based on predetermined criteria and involved many ANC visits. This approach was hard to implement effectively since many women had at least one risk factor, and not all developed complications; at the same time, some low risk women did develop complications. It is a burden on the healthcare system. As a result, many developing countries, including Ethiopia, are adopting focused antenatal care (FANC) approach. The newly proposed, FANC recommends four ANC visits for most pregnant women. Ideally, the first visit is in the first trimester but not after 16 weeks of gestation [2, 3].

The recommendation sets out from the fact that first trimester pregnancy stage is the fastest developmental period of the fetus, in which all organs become well developed and needs special attention $[4,5]$. However, too many women make their first antenatal visit with the pregnancy already compromised or at risk from smoking, inappropriate nutrition, ingestion of a variety of drugs, including pharmaceutical preparations, genitourinary tract infections, anemia and poor dental health [5].

Women present for antenatal care early in their pregnancy period allow enough time for essential and feasible interventions, prevention of complications and early identification of underlying conditions [6]. It also used to prevent, diagnose and treat sexually transmitted infections and work on the elimination of new Human Immune Deficiency Virus infections among new borne through providing integrated quality prevention of mother to child transmission [7-9].

Early attendance of ANC provides a better hemoglobin concentration through nutritional advice, prevention and early treatment of malaria and timely iron foliate supplementation [10, 11]. Beside this, it increases the opportunity of pregnant mothers to have more prenatal care visits, sufficient tests and advice during pregnancy and a skilled birth attendant $[12,13]$.

Mothers who start ANC after 22 weeks gestation, missed over four routine antenatal visits, who did not seek care or who concealed their pregnancy were manifest $17 \%$ of maternal deaths [14]. Suboptimal antenatal care was also found to be the major contributory factor for still birth in India [15]. Mothers who sought antenatal care before the end of the third month had infants who weighed heavier compared to the infants of mothers who sought care later $[11,16,17]$.

Even though there is improvement on antenatal care coverage and the World Health Organization recommendation is initiating ANC visit in the first trimester, the time of initiation of first ANC visit is varied throughout the world. In the Ethiopian context, it is recommended that the first ANC visit should be ideally taken place before 16 weeks of pregnancy (2). In order to improve maternal health care service utilization; all governmental health institutions of Ethiopia are providing focused antenatal care service for all pregnant mothers who come to the health institutions free of charge. Early initiation of antenatal care is promoted by health extension workers and health professionals in both urban and rural Keble's. Beside women developmental armies who are delegated in the community have their own role in community mobilization regarding to antenatal care service utilization.

According to the Ethiopia demographic, health survey, over $34 \%$ of pregnant women were attending antenatal care at least once. But, only $19 \%$ had four or more antenatal care visits during their entire pregnancy, and $11 \%$ of women made their first antenatal care visit before the fourth month of pregnancy nationwide [3]. In order to improve maternal and child health, identifying timing of first antenatal care visit among pregnant mothers and factors that affect initiation of first ANC visit is paramount. This study is designed to assess delay on first antenatal care visit among pregnant mothers and factors that affect initiation of first ANC.

\section{Methods}

\section{Study design and data sources}

An institutional based cross sectional study design was employed from February 1st through March 30, 2014 in public health facilities of Debremarkos town. Debremarkos town is the capital of East Gojjam Zone, which is located $300 \mathrm{~km}$ North West of Addis Ababa and $265 \mathrm{~km}$ away from regional capital Bahir Dar.

The study populations were pregnant women who visited public health facilities of Debremarkos town for antenatal care and randomly selected during the study period. Those pregnant mothers who were seriously ill or not aware their menstrual period were excluded from the study. The sample size was determined using single population proportion formula with the following assumptions: the proportion of delayed ANC is $74 \%$ from previous study conducted in Debre Birhan (18), maximum acceptable marginal error of $5 \%$, an alpha level of 0.05 and a none response rate $10 \%$ were used to obtain a sample size of 326 .

All public health facilities (one referral Hospital and three health centers) in Debremarkos town were included in the study. The total sample size was proportionally allocated to health facilities based on average monthly flow of pregnant mothers for ANC in each heath facility. The study subjects were recruited by using systematic random sampling technique after identification of the first study 
subject by simple random sampling method. Multiple enumerations due to referral were avoided using filtering questions.

The outcome variable of the study was delay on initiation of first ANC visit and the explanatory variables included Socio-demographic factors (age, religion, ethnicity, marital status, educational status, average monthly income), Obstetric factors (parity, History of obstetric complication, history of Previous ANC visit and intention of pregnancy),Enabling factors (accessibility of information about ANC and interaction with healthprofessional) and Reinforcing factors (perception of mothers on the advantage of the ANC, timing of ANC visit and frequency of the ANC; reasons that initiate mothers to start ANC after 16 weeks, a decision made to seek ANC, intention of partner to watrds ANC service utilization).

Delay on initiation of first antenatal care visit is initiation of first ANC visit in public health facilities which have skilled health personnel after 16 weeks of gestation.

Data were collected using structured interviewer administered questionnaire adopted from literatures and contextualized to the local situations and study objectives. The data collection tool was translated into the local language (Amharic) and pretested on 5\% of the actual sample size out of the study area. Four diploma nurses and one public health professional were involved as data collector and supervisor respectively after taking 1 day training.

\section{Ethical considerations}

The study was conducted after obtaining ethical clearance from Bahir Dar University, College of medicine and Health sciences, Research Ethics Committee and letter of support from Amhara regional health bureau ethical review committee. Formal Permission paper was given to woreda health office, Debremarkos Referal Hosipital and responsible persons in each health institution accordingly. Verbal informed consent also obtained from the study participants after explaining the purpose of study. Participants were informed on their full right to skip any question or terminate their participation at any stage. Participants were also assured that there will be no harm or benefit of being participating in this study. All the information from the respondents was kept confidential.

\section{Data processing and analysis}

The data were cleaned, coded and entered in Lauritsen JM, Bruus M, Myatt M. Epi Data.A comprehensive tool for validated entry and documentation of data. 2003; 3 and transferred to IBM SPSS Statistics for Windows, Version 20.0. Armonk, NY: IBM Corp for analysis. Both descriptive and inferential statistics were used to summarize the data. Those variables found to be statistically significant $(p<0.2)$ in the binary logistic regression analyses were entered into the multivariable logistic regression model and statistical significance was considered at $p<0.05$. The strength of association was assessed by odds ratio (OR) with $95 \%$ confidence interval.

\section{Results}

The response rate was $98.1 \%$. The mean $( \pm S D)$ age of respondents was $26.3( \pm 5.1)$.Among all respondents, 311 (97.2\%) were Amhara in ethnic group and majority 299(93.4\%) of mothers were orthodox Christian followers (Table 1).

Of all respondents, 107 (33.4\%) made their first ANC visit after 16 weeks of gestation. The mean time was 14 . $5( \pm 6.5)$ weeks with the range of 4 to 36 weeks. The median and the pick time was 12 weeks of gestation. Above

Table 1 Socio demographic characterstics of pregnant mothers who were attending ANC in the public health facilities of Debremarkos town, Feburary-March 2014 $(n=320)$

\begin{tabular}{|c|c|c|c|}
\hline Varaible & & Frequency & Percent \\
\hline \multirow[t]{2}{*}{ Residence } & Rural & 69 & 21.6 \\
\hline & Urban & 251 & 78.4 \\
\hline \multirow[t]{5}{*}{ Age } & $15-19$ & 16 & 5.0 \\
\hline & $20-24$ & 104 & 32.5 \\
\hline & $25-29$ & 121 & 37.8 \\
\hline & $30-34$ & 55 & 17.2 \\
\hline & $\geq 35$ & 24 & 7.5 \\
\hline \multirow[t]{2}{*}{ Ethinicity } & Amhara & 311 & 97.2 \\
\hline & Others & 9 & 2.8 \\
\hline \multirow[t]{2}{*}{ Relegion } & Orthodox chrstian & 299 & 93.4 \\
\hline & Muslim /Protestant & 21 & 6.6 \\
\hline \multirow[t]{3}{*}{ Marital status } & Never married & 14 & 4.4 \\
\hline & Married & 293 & 91.6 \\
\hline & Divorced/widowed & 13 & 4 \\
\hline \multirow[t]{4}{*}{ Educational status } & Have no formal education & 98 & 30.6 \\
\hline & Primary education & 51 & 15.9 \\
\hline & Secondary education & 87 & 27.2 \\
\hline & Tertiary education & 84 & 26.3 \\
\hline \multirow[t]{6}{*}{ Occupation } & Government employee & 81 & 25.3 \\
\hline & House wife & 49 & 15.3 \\
\hline & Merchant & 118 & 36.9 \\
\hline & Farmer & 42 & 13.1 \\
\hline & Daily labourer & 17 & 5.3 \\
\hline & Students / depende on family & 13 & 4.1 \\
\hline \multirow[t]{3}{*}{ Monthly income } & $<1000 \mathrm{ETB}(<\mathrm{Q} 1)$ & 124 & 38.8 \\
\hline & 1000-2987.50ЕTB & 116 & 36.2 \\
\hline & $>$ 2987.50ETB(>Q3) & 80 & 25.0 \\
\hline
\end{tabular}

Others $=$ Oromo/Tigrie/Agew 
half (51.2\%) of mothers were start their first ANC visit in the first trimester (Fig. 1) .

Among the total respondents,174 (54.4\%) were multiparous. Of these, 126 (74.2\%) reported that they had had experience of ANC for the preceding pregnancy. For those who had had ANC visit on preceding pregnancy, 43 (34\%) visited the ANC clinic for the first time after 16 weeks of gestation in the current pregnancy. From 68 (21.2\%) of mothers who had unintended pregnancy, 25 (36.8\%) indicated that they had interest in interrupting their pregnancy (Table 2).

The available health facilities were health centers for $220(68.8 \%)$ of respondents, Hospital for $60(10.8 \%)$ of respondents and health posts for $40(12.4 \%)$ of respondents. Of all respondents, 182 (56.9\%) were advised for ANC on current pregnancy. Of these, only 38 (20.9\%) had information on the time of first ANC visit. From those who had information on initiation time of ANC, 2 (5.3\%) were informed to start their first visit after 16 weeks of gestation (Table 3 ).

A majority, 27 (85.3\%) of respondents perceived that the ANC is important for both maternal and child health. Among delayed respondents 18 (16.8\%) were initiated ANC by considering the time of their visit at the right time (Fig. 2).

Among respondents 264 (82.5\%) were decided to seek ANC service jointly with their partners.From all, 287(89.4\%) partners supported the need of ANC for every pregnant mothers.

The bivariate analysis showed that pregnant mothers who were residing in rural areas[Crude Odds Ratio $(\mathrm{COR})=3.4$, 95\% Confidence Interval (CI): 2.01-6.07], not attained formal education $[\mathrm{COR}=4.5,95 \% \mathrm{CI}: 2.33-8.67]$, farmers $[\mathrm{COR}=7$. 8, 95\% CI: 3.37-18.05], having less than 1000 ETB average monthly income[COR $=2.7,95 \% \mathrm{CI}$ : $1.45-5.37]$,experience

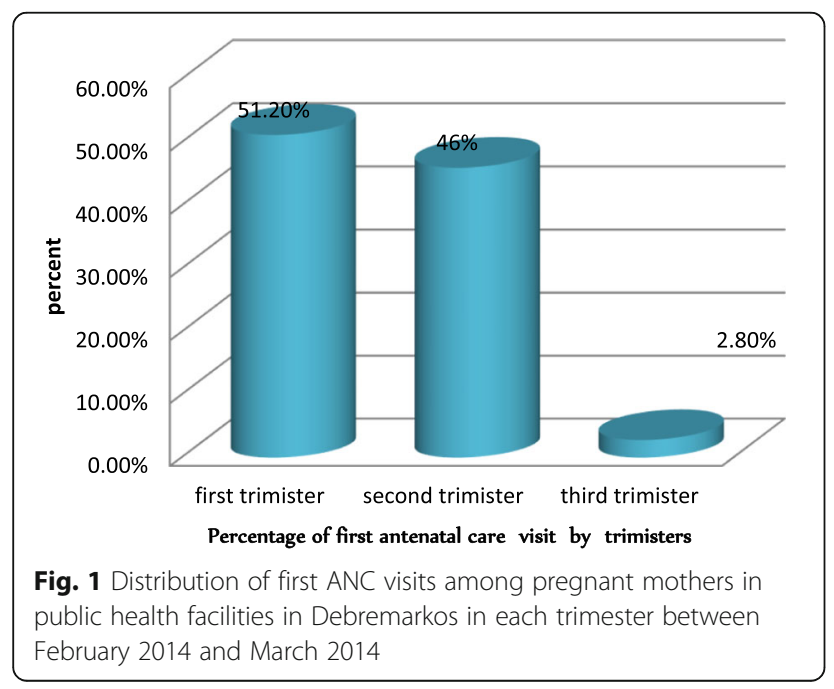

Table 2 Obstetric history of pregnant mothers, who were attending ANC in the public health Facilities of Debre Markos town, Feburary - March, $2014(n=320)$

\begin{tabular}{|c|c|c|c|}
\hline Variable & & Frequency & Percent \\
\hline \multirow[t]{2}{*}{ Gravidity $(n=320)$} & Primigravida & 146 & 45.6 \\
\hline & Multi gravida & 174 & 54.4 \\
\hline \multirow[t]{2}{*}{ Parity $(n=320)$} & No parity & 158 & 49.4 \\
\hline & $\geq 1$ parity & 162 & 50.6 \\
\hline \multirow{3}{*}{$\begin{array}{l}\text { Children born alive } \\
(n=174)\end{array}$} & 0 & 17 & 9.8 \\
\hline & $1-3$ & 135 & 77.6 \\
\hline & $\geq 4$ & 22 & 12.6 \\
\hline \multirow{2}{*}{$\begin{array}{l}\text { Death of children } \\
(n=157)\end{array}$} & Yes & 30 & 19.1 \\
\hline & No & 127 & 80.9 \\
\hline \multirow{2}{*}{$\begin{array}{l}\text { spontanous abortion } \\
(\mathrm{n}=174)\end{array}$} & Yes & 35 & 20.1 \\
\hline & No & 139 & 79.9 \\
\hline \multirow[t]{2}{*}{ stillbirth $(n=174)$} & Yes & 18 & 10.3 \\
\hline & No & 156 & 89.7 \\
\hline \multirow[t]{2}{*}{ History of ANC $(n=174)$} & Yes & 126 & 72.4 \\
\hline & No & 48 & 27.6 \\
\hline \multirow{2}{*}{$\begin{array}{l}\text { ANC initiation time on } \\
\text { Previous pregnancy } \\
(n=126)\end{array}$} & $\leq 16$ Weeks & 115 & 91.3 \\
\hline & > 16 Weeks & 11 & 8.7 \\
\hline \multirow{2}{*}{$\begin{array}{l}\text { Type of pregnancy } \\
\mathrm{N}=320\end{array}$} & Planned & 252 & 78.8 \\
\hline & Unplanned & 68 & 21.2 \\
\hline \multirow{2}{*}{$\begin{array}{l}\text { Intended to intrupt } \\
\text { unplannedPregnancy } \\
N=68\end{array}$} & Yes & 25 & 36.8 \\
\hline & No & 43 & 63.2 \\
\hline
\end{tabular}

Table 3 Availablity and accessability of health information among mothers who were attending ANC in the public health facilities of Debremarkos town, Feburary-March $2014(n=320)$

\begin{tabular}{llll}
\hline Variable & & Frequency & Percent \\
\hline Health education about & Yes & 85 & 67.5 \\
$\begin{array}{l}\text { ANCon previous pregnancy } \\
(n=126)\end{array}$ & No & 41 & 32.5 \\
Advised for ANC $(n=320)$ & Yes & 182 & 56.9 \\
& No & 138 & 43.1 \\
By whom you were advised & Husbands & 105 & 57.7 \\
$(n=182)$ & Healtrhextention & 28 & 15.4 \\
& Workers & & \\
& Relatives & 20 & 11 \\
& Friends/nigbours & 29 & 15.9 \\
Advised on initiation time & Yes & 38 & 20.9 \\
$(n=128)$ & No & 144 & 79.1 \\
Advised time $(n=38)$ & $\leq 16$ weeks & 36 & 94.7 \\
& $>16$ weeks & 2 & 5.3 \\
\hline
\end{tabular}




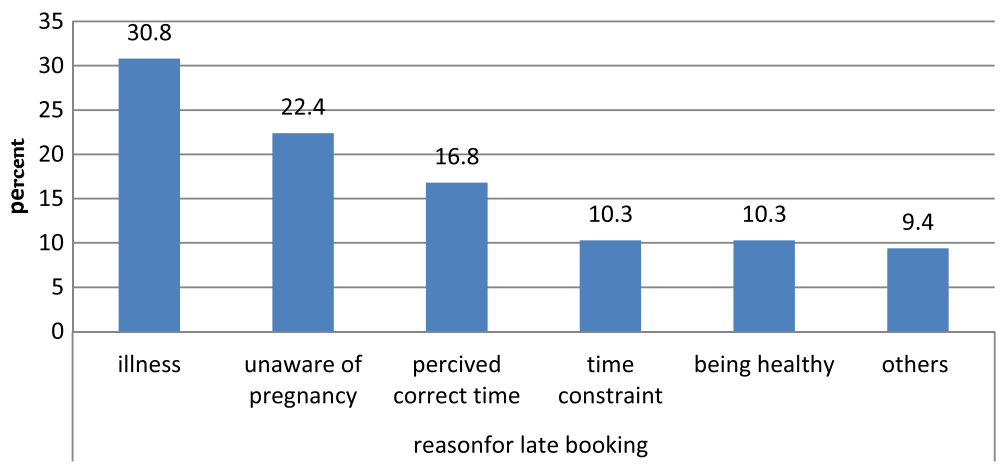

Fig. 2 Reasons for delay on first ANC visit among pregnant mothers who attended ANC in the public health facilities of Debre markos town between February 2014 and March 2014

one or more births [COR $=1.9,95 \% \mathrm{CI}: 1.22-3.15]$, not planned their pregnancy [COR $=3.9,95 \% \mathrm{CI}: 2.25-6.89]$, having a history of stillbirth [COR $=2.6,95 \%$ CI: $1.01-6.90]$ and those who perceived that the right time of first ANCvisit is after 16 weeks of gestation [COR $=3.8,95 \%$ CI: $1.69-9.76$ ] were more likely delayed on initiation of the first ANC visit. After adjusting for the potential cofounders; multivariable logistic regressionanalysis indicated that residence, educational status, intention of pregnancy and perception on the right time of first ANC visit were significantly associated with delayed first ANC visit.

Mothers who were residing in rural areas, not attainding formal education, having unplanned pregnancy and perciving the right time of ANC initiation as greater than 16 weeks of gestation were more likely delayed on first ANC visit (Adjusted Odds Ratio (AOR) $=2.8$ [95\% CI:1.54-5. $44]),(\mathrm{AOR}=2.2[95 \% \mathrm{CI}: 1.10-4.68]),(\mathrm{AOR}=3.6[95 \% \mathrm{CI}$ : 2.00-6.80]) and (AOR $=3.9[95 \% \mathrm{CI}: 1.61-9.76])$ respectivelly (Table 4).

\section{Discussion}

For many of the essential interventions in ANC, it is crucial to have early identification of underlying conditions. The first ANC visit should be as early as possible in pregnancy [10]. However, evidence in Ethiopia indicated that delayed ANC initiation time among pregnant mothers was high [18-21] .In our study,one third 107 (33.4\%) of respondents were delayed to start their first ANC visit with in the first 16 weeks of pregnancy. This finding is higher as compared to a study done in Bengazie $(27 \%, 2007)$ [22] . This might be due to difference in educational status of mothers between Bengazie and ours. But this finding is comparatively lower than the findings studied in Ndola (68.6\%) and Mpongwe (72\%) districts of Zambia [23] and South East Tanzania (81.5\%) [24], EDHS,2011(89\%) [25], Jimma University Specialized Hospital (60.1\%) [26], Kembata tembaro Zone (68.6\%) [27] and Dembech district of East
Gojjam Zone,North west Ethiopia (94.2\%) [28] .The possible explanation for this observed difference might be due to study population composition in which proportion of mothers residing in rural areas of current study were lower than other studies.

The finding also showed a significant association of residence and delay on timely initiation of ANC. Those mothers who were residing in rural areas were 2.8 times more likely delayed than urban mothers. Among all respondents, $56 \%$ of rural and $27 \%$ of urban residents were start ANC after 16 weeks of gestation. Ethiopian demographic and health survey, 2011, revealed that urban mothers made their first visit earlier (4.4 months) than rural mothers (5.5 months) [25]. This finding is also in agreement with the study done in Vietnam in which rural mothers were attained ANC latter and used fewer visits [29].

The possible reason might be better educational status of urban mothers than rular mothers. Because, in our study, $60 \%$ of rural mothers were not attaned formal education compared with $23 \%$ of urban mothers. The other reason might be availability of alternative health care facilities and having a better chance of health information in urban areas than rular areas. How ever, in contrary to our result,there was no significant difference in the proportionof delayed ANC attendance between urban and rular areas of Zambia [23].The reason for this difference might be the presence of more active mobile maternity service in rular than urbans areas of Zambia.

Educational status was found to have significant association with delayed initation of first ANC visit. Those mothers who had no formal education were delay two times more likely than those who had teritiary education. This is consistent with studies done in Gondar, Kembata tembaro zone,Tanzania and Ghana [11, 24, 27, 30 ] in which women who had lower education or none booked later than those with higher education. The reason might be high chance of exposure for information in case of educated mothers. 
Table 4 Factors associated with delay on first ANCvisit among pregnant mothers who were attending ANC in public health institutions of Debremarkos town,2014( $n=320)$

\begin{tabular}{|c|c|c|c|c|c|c|}
\hline \multirow[t]{2}{*}{ Variable } & & \multicolumn{2}{|l|}{ Delayed } & \multirow[t]{2}{*}{$\operatorname{COR}(\mathrm{Cl})$} & \multirow[t]{2}{*}{$\mathrm{AOR}(\mathrm{CI})$} & \multirow{2}{*}{$\begin{array}{l}P \text { - } \\
\text { Value }\end{array}$} \\
\hline & & Yes (\%) & No (\%) & & & \\
\hline \multicolumn{7}{|c|}{ Residence } \\
\hline & Rular & $39(12.2)$ & $30(9.4)$ & $3.4(2.01-6.07)$ & $2.8(1.54-5.44)^{\mathrm{a}}$ & 0.001 \\
\hline & Urban & $68(21.2)$ & 183(57.2) & 1.0 & 1.0 & \\
\hline \multicolumn{7}{|c|}{ Educational status } \\
\hline & Had no formaleducation & $54(16.9)$ & $44(13.8)$ & $4.5(2.33-8.67)$ & $2.2(1.10-4.68)^{a}$ & 0.027 \\
\hline & Primary education & $16(5)$ & $35(10.9)$ & $1.6(0.76-3.68)$ & $1.4(0.65-3.42)$ & \\
\hline & Secondary education & 19(5.9) & $68(21.3)$ & $1.0(0.49-2.12)$ & $0.8(0.40-1.87)$ & \\
\hline & Tertiary education & $18(5.6)$ & $66(20.6)$ & 1.0 & 1.0 & \\
\hline \multicolumn{7}{|c|}{ Occupation } \\
\hline & Government employee & $18(5.6)$ & 63(19.7) & 1.0 & 1.0 & \\
\hline & Merchant & $12(3.8)$ & $37(11.6)$ & $1.1(0.49-2.61)$ & $0.9(0.30-2.98)$ & \\
\hline & House wife & $34(10.6)$ & $84(26.3)$ & $1.4(0.73-2.73)$ & $1.0(0.37-2.94)$ & \\
\hline & Farmer & 29(9.1) & $13(4.1)$ & 7.8(3.37-18.05) & $2.2(0.52-9.51)$ & \\
\hline & Daily labourer & $9(2.8)$ & $8(2.5)$ & $3.9(1.32-11.67)$ & $1.5(0.33-7.21)$ & \\
\hline & Student / dependonfamily & $5(1.6)$ & $8(2.5)$ & $2.1(0.63-7.51)$ & $1.1(0.22-5.69)$ & \\
\hline \multicolumn{7}{|c|}{ Monthly Income } \\
\hline & $<1000$ ETB & $51(15.9)$ & $73(22.8)$ & $2.7(1.45-5.37)$ & $1.5(0.66-3.59)$ & \\
\hline & 1000-2987.50 ETB & $40(12.5)$ & $76(23.8)$ & $2.1(1.07-4.10)$ & 1.4(0.66-3.30) & \\
\hline & $>2987.50$ ETB & $16(5)$ & $64(20)$ & 1.0 & 1.0 & \\
\hline \multicolumn{7}{|l|}{ Parity } \\
\hline & No parity & $41(12.8))$ & 117(36.6) & 1.0 & 1.0 & \\
\hline & $\geq 1$ parity & $66(20.6)$ & $96(30)$ & $1.9(1.22-3.15)$ & $1.4(0.86-2.56)$ & \\
\hline \multicolumn{7}{|c|}{ Types of pregnancy } \\
\hline & Planned & $67(20.9)$ & 185(57.8) & 1.0 & 1.0 & \\
\hline & Unplanned & $40(12.5)$ & 28(8.8) & $3.9(2.25-6.89)$ & $3.6(2.00-6.80)^{a}$ & 0.000 \\
\hline \multicolumn{7}{|c|}{ Histrory of still birth } \\
\hline & No still birth & $97(30.3)$ & $205(64.1)$ & 1.0 & 1.0 & \\
\hline & $\geq 1$ still birth & $10(3.1)$ & $8(2.5)$ & $2.6(1.01-6.90)$ & $1.6(0.54-5.10)$ & \\
\hline \multicolumn{7}{|c|}{ Perceived time for 1st ANC visit } \\
\hline & $\leq 16$ weeks & $90(28.1)$ & 203(63.4) & 1.0 & 1.0 & \\
\hline & $>16$ weeks & $17(5.3)$ & $10(3.1)$ & $3.8(1.69-8.70)$ & $3.9(1.61-9.76)^{\mathrm{a}}$ & 0.003 \\
\hline
\end{tabular}

${ }^{\mathrm{a}}$ Statistical significant at $5 \%$ alpha level

Eventhough parity had no association with delayed initiation of ANC in our study, $40.7 \%$ of multiparous and $25.9 \%$ of nuliparous mothers were start thier first ANCvisit after 16 weeks of gestation.But, it was one of the factors for delayed initiation of ANC in different studies [13, 31, 32].

Intention of pregnancy was significantly associated with delay on initiation of first ANC visit. In this study, women with un planned pregnancy were 3.6 times more likely delayed to initiate first ANC visit than those mothers with planned pregnancy.This finding was inline with a study done in Kembata tembaro Zone [26]. Findings in different studies also in agreement with the association of unplanned pregnancy and delayed initiation of first ANC visit $[18,32-35]$. The possible reason might be mothers having intended pregnancy are much cautious and eger to know their pregnancy status and less likely delayed than those who had unintended pregnancy.

Intention of abortion in case of unintended pregnancymight also increased the chance of delayed initiation of ANC.Because, above half $14(56 \%)$ of pregnant mothers with unintended pregnancy, who looked for abortion did their first ANC visit after 16 weeks of gestation in our study. 
Perception on the right time of ANC initiation was found to be significantly associated with delayed ANC visit. Those mothers who perceived that the right initiation period of first ANC visit is beyond 16 weeks of gestation, were four times delayed than their counter part.

The Possible reason might be decreased exposure for information related to ANC initiation time. Because, in this study only $38(11.8 \%)$ of mothers have got information about initiation time of ANC from other persons. Other similar studies also suggested that proper information and advice on pattern of ANC utilization is important to book early [33]; where as, not knowing the right gestational age at which to start the first antenatal care visit was the commonest reason for late ANC attendance [36]. So, appropriate perception of the initial ANC visit was a factor for an early ANC visit. This is inagreement with a study done in Gondar University Hospital [30].

\section{Limitation of the study}

The study design is not strong enough to identify determinant factors.

\section{Conclusion}

The magnitude of delay on initiation of first ANC visit was still high but it is lower than studies conducted in other areas of Africa and Ethiopia.The time of initiation was ranges from first timester to third trimester and the mean gestational age on initation of first ANC was arround second trimester. According to this study residence, educational status, intention of pregnancy and perception on initiation time of ANC were influencing mothers on timely initiation of first ANC visit. Awarness creation towards timely initiation of first ANC visit and family planning utilization to prevent unplanned pregnancy should be strengthen by Zonal health department in the community specially for the reproductive age group and rural residents. Ministry of education should also improve women education by strengthening adult education in the community. Further study is recommended in the rural community.

\footnotetext{
Acknowledgements

First and for most thanks to the Almighty GOD who is our power. Our gratitude extends to East Gojjam Zone Plan and Economy department, East Gojjam zone health department, Debremarkos town adminstrative health office and health facilities.

We would like to thank Bahir Dar University and Debre Markos University for their financial and technical support.

We are also grateful to data collectors and study participants for giving us
} their valuable time.

\section{Availability of data and materials}

All the data supporting the study findings are within the manuscript. Additional detailed information and raw data are available from the corresponding author on reasonable request.

\section{Authors' contributions}

AA drafted the proposal, did the analysis, wrote the results and prepared the manuscript. AM participated on editing, analysis and write up of the result. BT, MM and BT were involved on data analysis and manuscript preparation. All authors read and approved the final manuscript.

\section{Ethics approval and consent to participate}

The study was conducted after obtaining ethical clearance from Bahir Dar University, College of medicine and Health sciences, Research Ethics Committee and letter of support from Amhara regional health bureau ethical review committe. Formal Permission paper was given to woreda health office, Debremarkos Referal Hosipital and responsible persons in each health institution accordingly. Verbal informed consent also obtained from the study participants after explaining the purpose of study. Participants were informed on their full right to skip any question or terminate their participation at any stage. Participants were also assured that there will be no harm or benefit of being participating in this study. All the information from the respondents was kept confidential.

\section{Competing interests}

The authors declare that they have no competing interests.

\section{Publisher's Note}

Springer Nature remains neutral with regard to jurisdictional claims in published maps and institutional affiliations.

\section{Author details}

'Department of Public Health, College of Health Sciences, Debre Markos University, Debre Markos, Ethiopia. ${ }^{2}$ Department of Public Health, College of Medicine and Health Science, Bahir Dar University, Bahir Dar, Ethiopia. ${ }^{3}$ Department of Midwifery College of Health Sciences, Debremarkos University, Debre Markos, Ethiopia. ${ }^{4}$ Department of Nursing, College of Health Sciences, Debre Markos University, Debre Markos, Ethiopia.

Received: 13 November 2017 Accepted: 19 April 2018

Published online: 16 May 2018

\section{References}

1. World Health Organization. Global health observatory $(\mathrm{GHO})$ data. URL. Available form: http://www.who.int/gho/publications/world_health_ statistics/2011/en/. 2015 Mar.

2. Ethiopian Federal Ministry of health. Antenatal Care Module: Providing Focused antenatalcare,FMOH.. http://www.open.edu/openlearncreate/mod/ oucontent/view.php?id=44\&printable $=1$.

3. Khanna J, Bergsjo P, Lashley K, Peters C, Sherrat D, Villar J. WHO antenatal care randomized trial: manual for the implementation of the new model. 2002. http://apps.who.int/iris/bitstream/10665/42513/1/WHO_RHR_01.30.pdf.

4. WHO. Essential Antenatal,perinatal and post partum care training module :promoting effective preinatal care. Copenhagen: World Health Organization regional office for Europe; 2002.

5. Abou-Zahr CL, Wardlaw TM, World Health Organization. Antenatal care in developing countries: promises, achievements and missed opportunities: an analysis of trends, levels and differentials, 1990-2001. 2003.

6. $\mathrm{FMOH}$. Accelerated Plan for Scaling up PMTCT Services in Ethiopia, Federal Minstry Of Health, Addis Ababa, Ethiopia. 2014.

7. Bollini P, Quack-Lötscher K. Guidelines-based indicators to measure quality of antenatal care. J Eval Clin Pract. 2013;19(6):1060-6.

8. World Health Organization. Global update on HIV treatment 2013: results, impact and opportunities. 2013.

9. East Gojjam zone health department: Annual report of East Gojjam zone health department, Debre markos, Ethiopia. 2013. Unpublished local report.

10. Lawn J, Kerber K. Opportunities for African newborns: practical data policy and programmatic support for newborn care in Africa. 2006.

11. Tayie FA, Lartey A. Antenatal care and pregnancy outcome in Ghana, the importance of women\'s education. African Journal of Food, Agriculture, Nutrition and Development. 2008:8(3):291-303.

12. Hueston WJ, Gilbert GE, Davis L, Sturgill V. Delayed prenatal care and the risk of low birth weight delivery in US. J Community Health. 2003;28(3):199-208.

13. Abeje $\mathrm{G}$, et al. Factors associated with institutional delivery service utilization among mothers in Bahir Dar city adminstration, Amhara region. Reprod Health. 2014;11(22):3-7. 
14. Bragg R, Action M. Money and Maternity: charging vulnerable pregnant women for NHS care. Maternity Action and Medact. 2013;26:1-9.

15. Saxena V, Bansal S, Chaturvedi J, Kalra BP, Chandra V, Kansal S. Investigating causes and factors associated with stillbirth by verbal autopsy in Uttarakhand. Indian J Prev Soc Med. 2011;42:14-8.

16. Alibekova R, Huang JP, Chen YH. Adequate prenatal care reduces the risk of adverse pregnancy outcomes in women with history of infertility: a nationwide population-based study. PLoS One. 2013;8(12):e84237.

17. Gebremariam A. Factors predisposing to low birth weight in JimmaHospital southwestern Ethiopia. East Afr Med J. 2005;8(1):554.

18. Zegeye $A M$, Bitew $B D$, Koye $D N$. Prevalence and determinants of early antenata care visit among pregnant women attending antenatal care in Debre Berhan health institutions, Central Ethiopia. Afr J Reprod Health. 2013;17(4):130-6.

19. Pell C, Meñaca A, Were F, Afrah NA, Chatio S, Manda-Taylor L, Hamel MJ, Hodgson A, Tagbor H, Kalilani L, Ouma P. Factors affecting antenatal care attendance: results from qualitative studies in Ghana, Kenya and Malawi. PLoS One. 2013;8(1):e53747.

20. Kebede B, Gebeyehu A, Andargie G. Use of previous maternal health services has a limited role in reattendance for skilled institutional delivery: crosssectional survey in Northwest Ethiopia. Int J Womens Health. 2013;5:79.

21. Fenta M. Assessment of factors affecting utilization of maternal health care services in Ayssaita and Dubti towns, afar regional state, north East Ethiopia. Master thesis, 2005.

22. Ziyo FY, Matly FA, Mehemd GM, Dofany EM. Relation between prenatal care and pregnancy outcome at Benghazi. Sudanese J Public Health. 2009;4(4): 403-10

23. Banda I, Michelo C, Hazemba A. Factors associated with late antenatal care attendance in selected rural and urban communities of the Copperbelt province of Zambia. Med J Zambia. 2012;39(3):29-36.

24. Gross K, Alba S, Glass TR, Schellenberg JA, Obrist B. Timing of antenatal care for adolescent and adult pregnant women in South-Eastern Tanzania. BMC Pregnancy Childbirth. 2012;12(1):16.

25. Demographic E. Health survey (2011) Addis Ababa. Ethiopia and Calverton: Central Statistical Agency and ICF International; 2012.

26. Ewnetu W, Assegid S, Wondafrash W, Ewnetu H. Factors associated with late antenatal care initiation in an Ethiopian clinic. Research. 2015.

27. Tekelab T, Berhanu B. Factors associated with late initiation of antenatal care among pregnant women attending antenatal Clinic at Public Health Centers in Kembata Tembaro zone, southern Ethiopia. Sci Technol Arts Res J. 2014;3(1):108-15.

28. Gedefaw M, Muche B, Aychiluhem M. Current status of antenatal care utilization in the context of data conflict: the case of Dembecha District, Northwest Ethiopia. Open J Epidemiol. 2014;4(04):208.

29. Toan TK. Antenatal and delivery care utilization in urban and rural contexts in Vietnam. A study in two health and demographic surveyllance sites. Gothenburg, Sweden. 2012

30. Belayneh T, Adefris M, Andargie G. Previous early antenatal service utilization improves timely booking: cross-sectional study at university of Gondar hospital, northwest Ethiopia. J Pregnancy. 2014;2014:1-7.

31. UmberJalil B, Yasmeen K, Razia N. Relation ship between maternal hemoglobin and prenatal out come, Pakistan railway hospital ,Rawalpindi. Rawal Med J. 2007;32:102-4.

32. Exavery A, Kanté AM, Hingora A, Mbaruku G, Pemba S, Phillips JF. How mistimed and unwanted pregnancies affect timing of antenatal care initiation in three districts in Tanzania. BMC Pregnancy Childbirth. 2013;13(1):35.

33. Tariku A, Melkamu Y, Kebede Z. Previous utilization of service does not improve timely booking in antenatal care: cross sectional study on timing of antenatal care booking at public health facilities in Addis Ababa. Ethiop Journal Health Dev. 2010:24(3).227-233.

34. Birmeta K, Dibaba Y, Woldeyohannes D. Determinants of maternal health care utilization in Holeta town, Central Ethiopia. BMC Health Serv Res. 2013:13(1):256.

35. Dibaba Y, Fantahun M, Hindin MJ. The effects of pregnancy intention on the use of antenatal care services: systematic review and meta-analysis. Reprod Health. 2013;10(1):50

36. Kisuule I, Kaye DK, Najijuka F, Ssematimba SK, Arinda A, Nakitende G, Otim L. Timing and reasons for coming late for the first antenatal care visit by pregnant women at Mulago hospital, Kampala Uganda. BMC Pregnancy Childbirth. 2013;13(1):121.

\section{Ready to submit your research? Choose BMC and benefit from:}

- fast, convenient online submission

- thorough peer review by experienced researchers in your field

- rapid publication on acceptance

- support for research data, including large and complex data types

- gold Open Access which fosters wider collaboration and increased citations

- maximum visibility for your research: over $100 \mathrm{M}$ website views per year

At BMC, research is always in progress.

Learn more biomedcentral.com/submissions 